\title{
The Impact of Workplace Bullying Behaviors on the Strategic Goals Fulfillment: A Field Study Conducted at the Jordan Customs Department (JCD)
}

\author{
Dr. Saleh Ibrahim Sulaiman Al-A'wasa \\ Human Resources Management \\ The Jordan Customs Department (JCD) \\ Dr. Shawqi Naji Jawad \\ Amman Arab University \\ Human Resources Management Department \\ Faculty of Business
}

\begin{abstract}
The study aimed at exploring the impact of the workplace bullying behavior on the fulfillment of the strategic goals at Jordanian Custom Department. Such behavior was measured through three dimensions; (the work-based bullying behavior, the interpersonal bullying behavior and the bullying behavior that is based on physical and verbal abuse). In order to fulfill the study's objective, the researchers developed a questionnaire for collecting the required data. A random sample was selected, and consisted 150 employees. The collected data was analyzed statistically through using descriptive and analytical statistical methods. In addition, multiple and simple regression analysis were used to analyze the collected data, to examine the study's hypotheses. It was concluded that there is a moderate impact for the workplace bullying measured by its dimensions on the fulfillment of the strategic goals. The researchers recommended the improvement of the interpersonal relationships among employees at each section of the Jordan Customs Department (JCD) through top management efforts.
\end{abstract}

Keywords: Strategic goals, workplace bullying.

\section{Introduction}

Human resources are considered significant pillars that support organizations. They have a significant impact on organizations' success and goals achievement. The fulfillment of the organization's goals is connected with its ability to carry out its tasks efficiently. Such fulfillment is also is connected with the management's ability to identify the factors that affect the level of productivity and efficiency provided by the human resources. Identifying such factors shall be reflected positively on the overall performance effectiveness of the organization (Monanu.2015).

Other researchers called the current century (the century of psychological pressures) due to the numerous psychological pressures facing people. Therefore, the performance level of employees at organization might be affected by factors surrounding them. Such factors may be personal factors and factors related to the workplace environment (Wang \& Shyu,2009). Due to the impact of the workplace environment on the employee's performance level, organizations' managements must create a suitable workplace environment. Management must provide employees with adequate attention and motivate them to exert more efforts at the workplace. Management can do that through $\mathrm{h}$ identifying factors that affect the employees' performance. They must also adjust these factors in a way that shall be reflected positively on employees' performance. That shall in turn raise the overall performance level of the organization. Managements must also identify the things that have a negative impact on employees' performance and exert efforts to adjust these things. That shall enable managements to enhance its relationship with employees, retain employees and maximize the employees' productivity level (Fapohunda,2013).

The workplace bullying considered a behavioral phenomenon that has been widely spreading at the workplace environments of numerous organizations. This phenomenon has a negative impact on employees' performance. Thus, it shall negatively affect the organizations’ performance level (Bunk \& Magley, 2013). 
Therefore, the researchers of the present study believe that it is necessary to examine this phenomenon (i.e. the workplace bullying). Studies about this issue might be needed to fight against it. Fighting against it shall participate in promoting positive social interaction among employees at the workplace environment. It shall participate in enhancing the interpersonal relationships at the workplace environment between employees and their supervisors. Having positive interpersonal relationships between employees might be reflected positively on the fulfillment of the organization's strategic goals.

\subsection{Statement of the Problem}

The workplace bullying behaviors are considered in appropriate behaviors that have been widely spreading at the workplace environments of numerous organizations. Such behaviors are usually committed in a regular manner at workplaces. It should be noted that such behaviors have a major impact on the performance of the Jordan Customs Department (JCD) and its employees. That is because these behaviors shall make the organizations incur many financial losses. Such an impact can be attributed to the negative consequences of these behaviors on employees' psychological conditions and performance level. For instance, these behaviors shall negatively affect the employees' job satisfaction, commitment, and organizational loyalty levels. It shall also negatively affect the employees' motivation to work and desire to achieve the goals of the aforementioned department. Therefore, the present study aimed at exploring the extent of spread of the workplace bullying behaviors at the Jordan Customs Department (JCD). The researchers also aimed at exploring the impact of those behaviors on the fulfillment of the strategic goals at the aforementioned department. It also aimed at suggesting mechanisms for fighting against those behaviors and reducing their negative impact on employees' performance level. The researchers suggested these mechanisms in order to enable the Jordan Customs Department (JCD) to achieve its strategic goals.

\subsection{The Study's Objectives:}

The present study aimed at examining the workplace bullying behaviors and identifying the extent of their spread at the Jordan Customs Department (JCD). It also aimed at identifying the impact of those behaviors on the fulfillment of the strategic goals at the Jordan Customs Department (JCD).

\subsection{The Study's Significance:}

The study's significance arises from the seriousness of the workplace bullying behaviors that are committed at governmental institutions in general and Jordan Customs Department (JCD) in particular. The present study might help in pinpointing the negative impacts of workplace bullying on institutions and individuals. The workplace bullying is a crucial case that has been recently dealt with by management studies. Thus, few management studies have explored this problem in the Arab world. In addition, the present study aimed at suggesting the changes must be made in the workplace environment of governmental institutions in order fight against the workplace bullying. These changes shall be useful for the Jordanian governmental institutions in general and the Jordan Customs Department (JCD) in particular.

\section{Literature Review:}

\subsection{The meaning of the expression (workplace bullying).}

The expression (workplace bullying) has been receiving much attention since the beginning of the third millennium. It has become a reason for feeling anxious by managements, employees, HR officers and any other people who are engaged in the workplace environment. Many researchers have exerted much effort to understand the workplace bullying behavior in order to fight against it and take measures against it. They exerted such effort due to its negative consequences on the workplace environment which make the management feel anxious (Fapohunda, 2013). There are various names for workplace bullying, such as: workplace deviation, workplace aggression, workplace violence, workplace harm, workplace abuse, organizational misbehavior, workplace harassment, workplace intimidation and etc.... (Tsiama, 2013).

Einarsen et al. (2010) suggested that workplace bullying involves several practices that employees face frequently (at least once a week). Such practices may be committed by the employee's colleagues or managers at the workplace over a specific period of time (six months or more). It may make the bullied employees feel humiliated and seek social isolation at the workplace. That would be reflected negatively on the work performance of the bullied employees. Mattice \& Garman (2011) suggest that workplace bullying involves systematic acts aggression and manipulation of the work mechanisms. 
According to the latter researcher, workplace bullying also involves acts that are committed to humiliate one person or more. They also state that workplace bullying creates unhealthy interpersonal and professional relationships between the bullies and the bullied employee. Thus, workplace bullying shall negatively affect the employees' psychological conditions and the fulfillment of the strategic goals. It shall negatively affect the overall performance of the organization.

Lutgan-Sandvik (2016) suggest that workplace bullying involves acts of verbal and non-verbal aggression are practiced frequently at the workplace. Such forms of aggression may includes: personal attacks, social rejection and many other painful methods that are practiced against employees. In other words, workplace bullying involves negative violent behaviors that are practiced by the bullies frequently against one employee or more at the workplace. Such behaviors aim to humiliate the employee, reject him socially, abuse him verbally, hinder his work and threaten him. These behaviors are committed frequently overall a long period of time (Lutgen-Sandvik, 2010)

\subsection{Forms of workplace bullying.}

The forms of workplace bullying found in three forms (Einrasen et al., 2009). These forms are presented below:

\subsubsection{Work-based bullying behaviors.}

Such negative behaviors target the employee in the aim of affecting his work performance negatively and accusing him that he is not exerting the required effort. Such behaviors may involve preventing the employee from having access to the information that needs which shall negatively affect his work performance. Such behaviors may also involve monitoring the employee excessively and demanding him to carry out tasks that exceed his capabilities and physical abilities.

\subsubsection{Interpersonal bullying behaviors.}

Such negative behaviors target the employee in the aim of humiliating and mocking him. They also aim at making him feel humiliated when dealing with others at the workplace. Such behaviors may involve circulating negative rumors about the employee and making him feel socially isolated at the workplace. Such behaviors may involve assigning meaningless tasks to him, criticizing him and reminding him constantly about his mistakes. Such behaviors may also involve making threat of dismissing him. They may also involve depriving him from some powers that he needs to carry out his tasks as required.

\subsubsection{Bullying behaviors based on physical and verbal abuse.}

Such negative behaviors target the employee in the aim of harming the employee physically and verbally. Such behaviors may involve verbal violence, workplace harassment, and workplace intimidation. They may also involve making threats about committing acts of physical violence against him many studies dealt with the workplace bullying and its negative consequences on people and organizations. For instance, Yuseon \& Kang (2016), Qureshi et al.(2014), Fapohunda (2013), and Nielsen \& Einarsen(2012) aimed at exploring the relationship between workplace bullying from one hand and organizational climate, and culture, and employees' commitment and job satisfaction from another hand. The latter researchers concluded that having high workplace bullying levels shall reduce employees' job satisfaction and organizational commitment levels.

The latter researchers concluded that there is a positive relationship between workplace bullying from one hand and the organizational climate and culture from another hand. Giorgi et al.(2013), Oladapo\& Thornton (2013), Catley et al.(2013), and Georgakopoulos et al.(2011) aimed at identifying the extent of spread of the workplace bullying behavior, their reasons and impacts. The said studies were conducted due to the seriousness and negative impacts of the workplace bullying behaviors on people and organizations. The latter researchers concluded that the workplace bullying behaviors have a statistically significant impact on the individual and organization. The latter researchers also concluded that there is a positive relationship between employees' characteristics and the workplace bullying behaviors

\section{Strategic goals}

The word goals refer to results that the organization seeks to achieve through its services or products. Organizations usually seek to provide their services or products with certain qualities to fulfill their goals. In other words, the word goals refer to the final results of activities (Goetsch, \& Davis, 2010). Goals can be also defined as the results that must be reached in order to translate the organization's mission into actions during a specific period of time and within taking the surrounding changes into account (David, 2001). 
Griffin (2002) suggests that goals are the things that drive organizations to work and operate. The view of the latter researcher reflects the significance of having strategic goals for organizations. These goals are considered the most important element of the planning process. They also guide the top management when making decisions. They also help the top management in setting the goals that must be fulfilled by the middle and line management. They also help the top management in identifying the powers and positions that must be given for each employee. In addition, goals also affect the relationships between employees. They also enable the management to set standards and criteria that shall govern the control processes. In addition, having strategic goals shall facilitate the process of assessing the employees' performance.

The main goal of any business organization is represented in survival. However, this goal is connected with the organization's ability to grow and gain profits. Through surviving in the world of competition, organization shall have the ability to fulfill their long-term and short-term strategic goals. These goals may change throughout time in accordance with the requirements of the changing environment. For instance, several dominant organizations may emerge in the market which shall affect the plans and goals of the other organizations.

\section{The Study's Methodology:}

\subsection{Population and Sample}

The population of the present study is represented in the employees who work at the Jordan Customs Department (JCD). As for the study's sample, it consists of 150 employees who were selected from the study's population. The questionnaire forms were distributed the sample. However, 133 questionnaire forms were retrieved and all of them are valid for statistical analysis. Thus, the response rate is $88.6 \%$.

\subsection{The Study's Instruments:}

The researchers developed a questionnaire in order to collect the required data from the respondents. It was developed in accordance with the study's questions and hypotheses. To be specific, the questionnaire consists of three parts. These parts are illustrated below: The first part: It aims to collect the respondents' demographic data, such as: gender, age, academic qualification, major and years of experiences.

The second part: It aims to measure the extent of spread of the workplace bullying behaviors at the Jordan Customs Department (JCD) through using a scale. The workplace bullying is considered the independent variable. Seven (7) items aimed at measuring the work-based bullying behavior. Twelve (12) items aimed at measuring the interpersonal bullying behavior. Three (3) items aimed at measuring the bullying behavior that is based on physical and verbal abuse. This scalewas developed in accordance with the scale of Einarsen, Hoel \& Notelaers(2009). The latter scale was adapted with the nature of the study's population and the Jordan Customs Department (JCD).

The third part: This part is concerned with the impact of the workplace bullying behaviors on the fulfillment of the strategic goals of the Jordan Customs Department (JCD). The extent of fulfilling the strategic goalsis considered the dependent variable. Ten (10) items aimed at measuring this variable.

The study's instrument adopts the five point Likert scale. Thus, five multiple answers were provided for each item; (strongly agree, agree, neutral, disagree, and strongly disagree). The scores of these answers are $(5,4,3,2$, and 1) respectively

\subsection{The Study's Model:}

The independent variable The workplace bullying

\section{The dependent variable The strategic goals:}

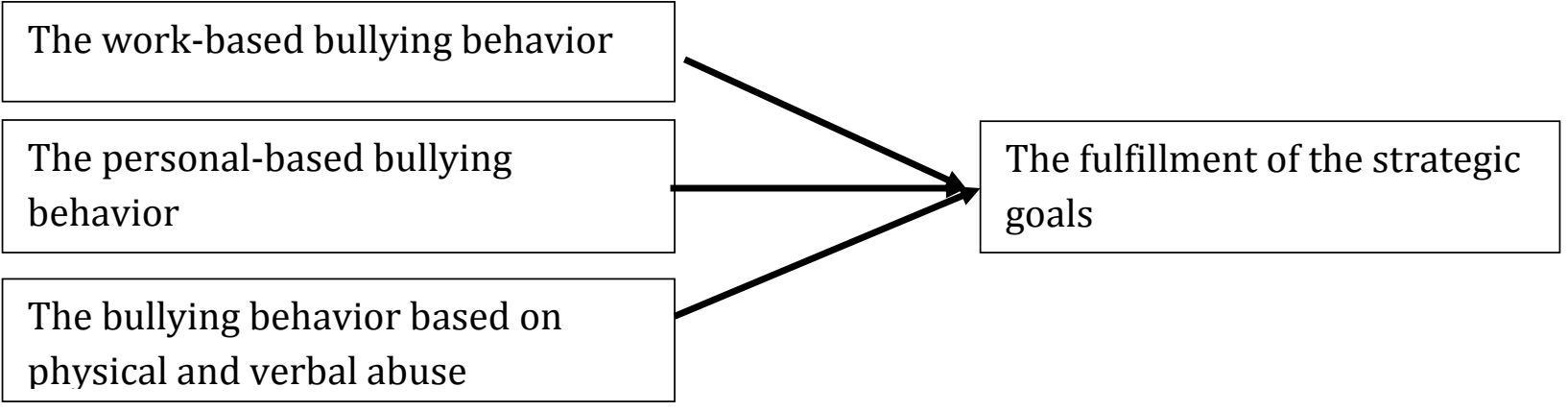


The researchers of the present study developed this model based on the studies conducted by Eisele (2016); Jiyeon \& Kang (2016); and Einarsen, Hoel \& Notelaers (2009).

\subsection{The variance inflation factor (VIF)}

The variance inflation factor (VIF) values were calculated to measure the severity of multicollinearity between the independent variables. The variance inflation factor (VIF) value of the work-based bullying behavior is 4.418, whereas the variance inflation factor (VIF) value of the interpersonal bullying behavior is 3.268. As for the variance inflation factor (VIF) value of the bullying behavior that is based on physical and verbal abuse, it is 1.955. All these values are less than 10. Thus, there isn't any multicollinearity between the study's independent variables (Sekaran, 2003).

\subsection{Normality tests}

After conducting the normality test, it was concluded that the study's data is distributed normally according to the central limit Theorem theory. The latter theory suggests that when the respondents are more than thirty, the data is distributed normally. In addition, the values of the skewness and Kurtosis coefficients were calculated. These values are less than 2. That means that the study's data is distributed normally (Sekaran, 2003). The values of the skewness and Kurtosis coefficients are presented in table (1) below:

Table (1): The results of the normality tests

\begin{tabular}{|c|c|c|}
\hline Variable & $\begin{array}{ll}\begin{array}{l}\text { The } \\
\text { efficient }\end{array} & \text { skewnessco } \\
\end{array}$ & \begin{tabular}{|ll}
$\begin{array}{l}\text { The } \\
\text { coefficient }\end{array}$ & Kurtosis \\
\end{tabular} \\
\hline The work-based bullying behavior & 0.323 & 1.045 \\
\hline The interpersonal bullying behavior & 0.171 & 1.059 \\
\hline $\begin{array}{l}\text { The bullying behavior that is based on physical and verbal } \\
\text { abuse }\end{array}$ & 0.387 & 0.915 \\
\hline The strategic goals & 0.891 & 0.417 \\
\hline
\end{tabular}

\subsection{The Statistical Analysis Methods:}

The present study used several statistical methods to analyze the collected data and test the study'shypotheses. For instance, the researchers calculated frequencies, arithmetic means, standard deviations and Pearson correlation coefficient. The researchers also conducted the multiple and simple regression analysis in order to test the study's hypotheses.

\subsection{The validity and reliability of the study's instrument:}

The values of the Cronbach's alpha coefficient $(a)$ were calculated for the statements of each variable. In addition, the overall value of the Cronbach's alpha coefficient $(a)$ was also calculated. These values were calculatedto measure the reliability of the study's instrument. All these values are greater than 0.60 . That indicates that the study's instrument is highly reliable and provide reliable results (Sekaran, 2003).

Table (2): The values of the Cronbach's alpha coefficient

\begin{tabular}{|l|l|l|l|l|l|}
\hline Variable & $\begin{array}{l}\text { The work-based } \\
\text { bullying } \\
\text { behavior }\end{array}$ & $\begin{array}{l}\text { The } \\
\text { interpersonal } \\
\text { bullying behavior }\end{array}$ & $\begin{array}{l}\text { The bullying } \\
\text { behavior based on } \\
\text { physical and } \\
\text { verbal abuse }\end{array}$ & $\begin{array}{l}\text { The strategic } \\
\text { goals }\end{array}$ & Total \\
\hline$a$ & $\mathbf{0 . 7 9 1}$ & $\mathbf{0 . 8 4 2}$ & $\mathbf{0 . 8 2 1}$ & $\mathbf{0 . 8 6 3}$ & $\mathbf{0 . 8 6 9}$ \\
\hline
\end{tabular}

\section{The Study's Results:}

\subsection{The Characteristics of the study's sample:}

Frequencies and percentages were calculated to identify the characteristics of the study's sample. It was concluded that $83.5 \%$ of the respondents are males (111 males). It was concluded that $16.5 \%$ of the respondents are females ( 22 females). That means that the Jordan Customs Department (JCD) aims to recruit males more than females. That is attributed to the nature of the works at the latter department. For instance, the locations of the centers of the latter department on the borders make it necessary to recruit males more than females. It was concluded that $66 \%$ of the respondents are less than 45 years. 
That means that the Jordan Customs Department (JCD) aims to recruit young people. That is because young people are characterized with being energetic, active and motivated to work. They also embrace changes more than others. It was also concluded that $81 \%$ of the respondents have more than five (5) years of experience. It means that the Jordan Customs Department (JCD) aims to recruit the ones who have many years of experience. It was concluded that $71.4 \%$ of the respondents hold (BA, MA, and PhD) degrees. That is considered a high percentage. It means that the Jordan Customs Department (JCD) aims to recruit the ones who have high academic qualifications. In addition, it was also concluded that $86.7 \%$ of the respondents hold degrees in accounting, management or economy. That means that the latter department tends to recruit employees who are specialized in a sub-specialty.

\subsection{The descriptive statistical methods.}

Based on table (3), it can be noticed that the arithmetic means of the workplace bullying dimensions are very close to one another. For instance, the arithmetic mean of the work-based bullying behavior is 3.52, whereas the arithmetic mean of the interpersonal bullying behavior is 3.51. The latter values are considered high. As for the arithmetic mean of the bullying behavior that is based on physical and verbal abuse, it is 3.38. The latter value is considered moderate. As for the standard deviations of the workplace bullying dimensions, they indicate that respondents' answers vary, especially for the statements that concern the work-based and interpersonal bullying behaviors. As for the standard deviation of the bullying behavior that is based on physical and verbal abuse, it shows a lower value.

As for the impact of the workplace bullying on the fulfillment of strategic goals, it shows a high mean which is 3.76. The standard deviation of this impact is 0.806 . That indicates that the workplace bullying has a significant impact on the fulfillment of strategic goals of the Jordan Customs Department (JCD). Based on table (3), it can be noticed that there is a bivariate correlation between the study's variables. It can be noticed that there is a negative relationship of moderate strength between the workplace bullying and the fulfillment of the strategic goals. This relationship is statistically significant at the significance level of ( $\mathrm{Sig}<0.05)$.

Table (3): The arithmetic means, standard deviations and values of the bivariate linear correlation coefficient

\begin{tabular}{|c|c|c|c|c|c|c|c|}
\hline No. & Variable & $\begin{array}{c}\text { Arithmetic } \\
\text { mean }\end{array}$ & $\begin{array}{c}\text { Standard } \\
\text { deviation }\end{array}$ & $\mathbf{1}$ & $\mathbf{2}$ & $\mathbf{3}$ & $\mathbf{4}$ \\
\hline 1 & The work-based bullying behavior & 3.52 & 1.059 & 1 & & & \\
\hline 2 & The interpersonal bullying behavior & 3.51 & 0.918 & $* * 0.832$ & 1 & & \\
\hline 3 & $\begin{array}{c}\text { The bullying behavior that is based } \\
\text { on physical and verbal abuse }\end{array}$ & 3.38 & 1.186 & $* * 0.697$ & $* * 0.552$ & 1 & \\
\hline 4 & The strategic goals & 3.76 & 0.806 & $* * 0.532$ & $* * 0.427$ & $* * 0.733$ & 1 \\
\hline
\end{tabular}

$*$ The criterion that the researchers adopted for classifying the arithmetic means is the following:

a)- (3.5 or more): high; b)- (3.49-2.5): moderate; and c)- (2.49 or less): low

\section{Testing the Study's Hypotheses:}

\subsection{Testing the main hypothesis:}

H0.1: There isn't any statistically significant impact for the workplace bullying dimensions on the fulfillment of strategic goals of the Jordan Customs Department (JCD).

Table (4): The results of testing the main hypothesis

\begin{tabular}{|l|l|l|l|l|l|l|}
\hline Dimension & R & B & Beta & T & Sig. & Result \\
\hline Constant & & 2.037 & & 8.832 & 0.000 & $\begin{array}{l}\text { Statistically } \\
\text { significant }\end{array}$ \\
\hline $\begin{array}{l}\text { Workplace } \\
\text { bullying }\end{array}$ & $* * 0.560$ & 0.493 & 0.560 & 7.730 & 0.000 & $\begin{array}{l}\text { Statistically } \\
\text { significant }\end{array}$ \\
\hline F Coefficient & 59.748 & & & & & \\
\hline $\mathrm{R}^{2}$ Coefficient & 0.313 & & & & & \\
\hline
\end{tabular}

$*$ Sig $<0.05$ 
The multiple regression analysis was conducted in order to test the main hypothesis mentioned above. Based on table (4), it can be noticed that the calculated $F$ value is (59.748). The latter value is statistically significant at the significance level of Sig <0.05. Thus, the null hypothesis mentioned above is rejected. That means that the workplace bullying dimensions have a statistically significant impact on the fulfillment of strategic goals of the Jordan Customs Department (JCD).However, the strength of the impact is moderate. That was concluded through the value of $R$, which is 0.560 .

It was concluded that the independent variable can interpret $31.3 \%$ of the changes that occur in the dependent variable. In addition, the calculated t value of the workplace bullying is 7.730 which is statistically significant at the significance level of ( $\mathrm{Sig}<0.05)$. This value confirms that the workplace bullying has a statistically significant impact on the fulfillment of strategic goals of the Jordan Customs Department (JCD). As for Beta value, it is 0.560 which is statistically significant at the significance level of ( $\mathrm{Sig}<0.05)$. This value reflects the extent to which the workplace bullying affects the fulfillment of strategic goals at the Jordan Customs Department (JCD).

\subsection{Testing the study's sub-hypotheses.}

H0.1.1:There isn't any statistically significant impact for the work-based bullying behavior on the fulfillment of strategic goals of the Jordan Customs Department

H0.1.2: There isn't any statistically significant impact for the interpersonal bullying behavior on the fulfillment of strategic goals of the Jordan Customs Department

H0.1.3: There isn't any statistically significant impact for the bullying behavior that is based on physical and verbal abuse on the fulfillment of strategic goals of the Jordan Customs Department

Table (5): The results of testing the study's sub-hypotheses

\begin{tabular}{|c|c|c|c|c|c|}
\hline & \multicolumn{4}{|c|}{ Dependent variable } \\
\hline & & \multicolumn{4}{|c|}{ strategic goals } \\
\hline Hypothesis & Independent variable & $\mathrm{F}$ & Sig. & $\mathrm{R}$ & $\mathrm{R}^{2}$ \\
\hline H0.1.1 & The work-based bullying behavior & 51.755 & 0.000 & $* * 0.532$ & 0.283 \\
\hline H0.1.2 & The interpersonal bullying behavior & 29.285 & 0.000 & $* * 0.427$ & 0.183 \\
\hline H0.1.3 & $\begin{array}{l}\text { The bullying behavior that tis based on } \\
\text { physical and verbal abuse }\end{array}$ & 152.387 & 0.000 & $* * 0.733$ & 0.538 \\
\hline
\end{tabular}

$*$ Sig $<0.05$

The simple regression analysis was conducted in order to test the hypotheses mentioned above. Based on table (5), it can be noticed that the calculated $\mathrm{F}$ value of the work-based bullying behavior is 51.755, whereas the calculated $F$ value of the interpersonal bullying behavior is 29.285. It can be also noticed that the calculated $F$ value of the bullying behavior that is based on physical and verbal abuse is 152.387. All of these values are statistically significant at the significance level of (Sig < 0.05). Thus, the three null sub-hypotheses are rejected. That means that all the three dimensions have a statistically significant impact on the fulfillment of strategic goals of the Jordan Customs Department (JCD).

The strength of the relationship between the work-based bullying behavior and the fulfillment of strategic goals is 0.532. The strength of the relationship between the interpersonal bullying behavior and the fulfillment of strategic goals is 0.427 .The strength of the relationship between the bullying behavior that is based on physical and verbal abuse and the fulfillment of strategic goals is 0.733 . The work-based bullying behavior can interpret $28.3 \%$ of the dependent variable. The interpersonal bullying behavior can interpret $18.3 \%$ of the dependent variable. The bullying behavior based on physical and verbal abuse can interpret $53.8 \%$ of the dependent variable

\section{Results}

The results indicate that there is a high level of workplace bullying at the Jordan Customs Department (JCD) from the perspective of the employees who work there. The workplace bullying behavior was measured by three dimensions; (the work-based bullying behavior, the interpersonal bullying behavior and the bullying behavior that is based on physical and verbal abuse).

It was concluded that the work-based bullying behaviors are highly practiced in the Jordan Customs Department (JCD). 
For instance, it was concluded that the mean of statement (7) is the highest mean among the work-based bullying statements. The mean of the latter statement is 3.72. The latter statement states the following: (The manager excessively monitors his subordinates). It was also concluded that the mean of statement (5) is the second highest mean among the work-based bullying statements. The mean of the latter statement is 3.71. The latter statement states the following: (The employee faces many pressures to prevent him from claiming any of his rights. Such rights may include: getting a sick leave or any of his entitlements). It was concluded that mean of statement (6) is the third highest mean among the work-based bullying statements. The mean of the latter statement is 3.64. The latter statement states the following: (The employee feels that his efforts are not appreciated enough by the management).

It was concluded that the interpersonal bullying behaviors are highly practiced in the Jordan Customs Department (JCD). For instance, it was concluded that the mean of statement (8)is the highest mean among the interpersonal bullying statements. The mean of the latter statement is 3.83. The latter statement states the following: (Some employees mock their colleagues at work). It was concluded that the mean of statement (17) is the second highest mean among the interpersonal bullying statements. The mean of the latter statement is 3.77 . The latter statement states the following: (Some employees show disrespect for their colleagues at work). It was concluded that the mean of statement (18) is the third highest mean among the interpersonal bullying statements. The mean of the latter statement is 3.71. The latter statement states the following: (The employee does not get rewards despite the fact that he has earned them).

It was concluded that the mean of statement (19) is the fourth highest mean among the interpersonal bullying statements. The mean of the latter statement is 3.62. The latter statement states the following: (The employee is threatened of getting dismissed).

It was concluded that the level of the bullying behavior that is based on physical and verbal abuse is moderate. It was concluded that that the mean of statement (20) is the highest mean among the statements that concern the bullying behavior that is based on physical and verbal abuse. The mean of the latter statement is 3.35. The latter statement states the following: (The employee is threatened of using verbal violence against him). It was concluded that that the mean of statement (22) is the highest mean among the statements that concern the bullying behavior that is based on physical and verbal abuse. The mean of the latter statement is 3.49. The latter statement states the following: (The employee suffers from physical, visual and verbal harassment at the workplace)

It was concluded that workplace bullying has a statistically significant impact on the fulfillment of strategic goals. The mean of statement (26) is 3.82. The latter statement states the following: (The workplace bullying behavior affects the employees' morale).

It was concluded that that the mean of statement (27) is 3.89. The latter statement states the following: (The workplace bullying raises the absence from work rates among employees). As for the mean of statement (28), it is 4.15. The latter statement states the following: (The workplace bullying can significantly reduce the productivity levels). As for the mean of statement (30), it is 4.05. The latter statement states the following: (The workplace bullying reduces the interaction between employees when setting the strategic goals). As for the mean of statement (32), it is 4.02. The latter statement states the following: (The workplace bullying can lead to dissipating employees' energies when setting the strategic goals).It was concluded that there is a negative relationship between workplace bullying dimensions and the extent of fulfillment of strategic goals at the Jordan Customs Department (JCD). The strength of this relationship is moderate. It was also concluded that the workplace bullying dimensions have a statistically significant impact on the extent of fulfillment of strategic goals at the Jordan Customs Department (JCD). These dimensions are: (the work-based bullying behavior, the interpersonal bullying behavior and the bullying behavior that is based on physical and verbal abuse).

\section{Recommendations}

In the light of the study's results, the researchers of the present study suggest several recommendations. For instance, they recommend providing more attention to the interpersonal relationships among employees by the top management of the Jordan Customs Department (JCD). The researchers also believe that the latter management should deal properly and respectfully with the employees without undermining their dignity. The researchers also believe that the latter management should enhance its interpersonal relationships with the employees. The researchers believe that the top management should be keen to collect accurate and full information about work issues to make good decisions that are not bias. 
The researchers believe that the top management should discuss its decisions with the employees involved in the decisions. That should be done before issuing the decisions. The top management should empower the employees with the suitable powers and information that enable them to carry out their duties as required. Furthermore, the researchers believe that the top management should hold periodical meetings with the employees in order to discuss the problems faced by them. That should be done to find solutions for their problems.

\section{References}

Bunk, J. A., Magley, V. J. (2013). The role of appraisals and emotions in understanding experiences of workplace incivility. Journal of occupational health psychology, 18(1), PP 87.

Catley,B.Bentley,T.Forsyth,D.Cooper-Thimas,H.Dianne Gardenr,D.

O'driscoll,M.Trenberth,L.(2013). Managing workplace bullying in New Zealand: Perspectives from occupational health and safety practitioners, Journal of Management \& Organization, Vol (19), Issue (5), pp. 598-612.

David, Fred R. (2001). Strategic Management: Concepts \& Cases.Upper Saddle River, New Jersey: Pearson Prentice Hall.

Einarsen, S., Hoel, H., and G. Notelaers. (2009). "Measuring exposure to bullying and harassment at work: Validity, factor structure and psychometric properties of the Negative Acts Questionnaire - revised," Work and Stress, 23(1), 24-44.

Einarsen, S., Skogstad, A., Rørvik, E., Lande, A.B., and M.B. Nielsen. (2016). "Climate for conflict management, exposure to workplace bullying and work engagement: a moderated mediation analysis," The International Journal of Human Resource Management, Vol(23),Issue (1), PP 1-22.

Fapohunda, T. M.(2013). Managing Workplace Bullying. Journal of Human Resource Management. Vol. 1, No. 3,pp. 39-47.

Georgakopoulos,A. Wilkin,L. Kent,B. (2011). Workplace Bullying: A Complex Problem in Contemporary Organizations, International Journal of Business and Social Science Vol. 2 No. 3,PP 1-20.

Giorgi, G., Ando, M., Arenas, A., Shoss, M. K., \& Leon-Perez, J. M. (2013). Exploring personal and organizational determinants of workplace bullying and its prevalence in a Japanese sample. Psychology of Violence, 3(2), 185-197.

Goetsch, David L. \& Davis, Shanley B. (2010) Quality Management for Organization Excellence: Introduction to Total Quality, Upper Saddle River,NewJersey: Person Education Inc, Sixth Edition.P65.

Griffin, Ricky W. (2002). Management. 7th ed. Boston: HoughtonMifflin Company.

Lutgen-Sandvik, P.(2010).The communicative cycle of employee emotional abuse: Generation and regeneration of workplace mistreatment. Management Communication Quarterly,16(4),471-501.

Mattice\& Garman,(2011). Building a culture of respect:Managing bullying at work (pp. 135-154). London: Taylor \& Francis.

Monanu O, G. Okoli I, E. Adibe C, G. (2015). Examining the link between organizational justice and counterproductive work behavior. Journal of Business \& Management Studies,Vol (1) Issue(2),PP 1-10.

Nielsen,M,B. \&Einarsen,S. (2012). Outcomes of exposure to workplace bullying: A meta-analytic review, An International Journal of Work,Health \& organizations, Vol (26),Issue (4),PP309-332.

Oladapo,V. Thornton,L. (2013). Management Bullies: The Effect on Employees, Journal of Business Studies Quarterly, Vol 4, No.4, PP 1-14.

Qureshi,M,I. Rasli,A,M. Zaman,K. (2014). A New Trilogy to Understand the Relationship among Organizational Climate, Workplace Bullying and Employee Health, Arab Economics and Business Journal 9, PP133146.

Sekaran, U. (2003). Research methods for business (4th ed.). Hoboken, NJ: John Wiley \& Sons.

Tsiama, M.C. (2013). "The phenomenon of Moral Psychological Harassment at Work: a conceptual approach," National Institute of Employment and Human Resources, 9,PP 4-27.

Wang,S. Shyu, C, L. (2009). The longitudinal effect of HRM effectiveness and dynamic innovation performance on organizational performance in Taiwan. International Journal of Human Resource Management, Vol(20),Issue (8), PP 1790- 1809.

Yuseon,A. Kang, J. (2016). Relationship between Organizational Culture and Workplace Bullying among Korean Nurses, Asian Nursing Research, 10, 234-239. 